\title{
Venereal disease education in West Virginia, USA
}

\author{
JOSEPH C. FRANZ AND ROLAND J. WEISSER JR \\ From the Committee for Venereal Disease Education, West Virginia University, \\ Morgantown, West Virginia, USA
}

SUMMARY A venereal disease educational programme entitled Venereal Disease Education in West Virginia was constructed. It consisted of a preliminary test to assess the level of general knowledge of venereal diseases, a value survey list, a lecture illustrated by colour slides, and a final test. The programme was presented to 3210 students in Northcentral West Virginia who ranged in age from 12 to 20 years ( 7 th to 12 th grade). The mean score in the preliminary test was 7.97 $(53 \%)$ correct answers out of 15 , and the mean score for the final test was $11.55(77 \%)$ correct answers out of 15 . The ability of students to retain the information given to them was measured by testing the same class of 53 students one year later. These students obtained a mean score of $11.41(76 \%)$ correct answers out of 15 in the later test which demonstrates that the students had retained much of the information.

\section{Introduction}

The assignment of responsibility for venereal discase education in schools is often discussed. Until October 1975, venereal disease education in schools in West Virginia had been largely the responsibility of the state Health Department, but limited manpower and lack of money had prevented a major attack being made. The Health Department had mainly concentrated on distributing pamphlets but occasionally field health officers had run courses on venereal diseases. There had also been sponsored roadside advertisements, and announcements for television and radio. In some areas local physicians had given their time to schools while in others the topic was lightly covered by various courses on health education, physical education, or human sexuality. These efforts could be described as sporadic.

This paper describes an educational programme developed and tested during the last two years by the Committee for Venereal Disease Education of the West Virginia University Medical Center. The programme is unique in at least two respects. Firstly, the manpower is derived from energetic students studying medicine, pharmacy, or nursing at West Virginia University Medical Center. Secondly, it integrates tests, with lectures and discussion groups so that the 'package' provides an educational

\footnotetext{
Address for reprints: J. C. Franz MD, Committee for VD Education, Box 1161, Medical Center, West Virginia University, Morgantown, West Virginia 26506, USA

Received for publication 30 June 1977
}

'learning experience' rather than just a didactic presentation, and some measure of its effectiveness is available.

\section{Methods}

The venereal disease educational programme comprised a preliminary test on venereal disease in general, a value survey list, a lecture illustrated with colour slides, and a final test. It was reviewed and approved by state and local Health Department officials and by the Public School Superintendents and Boards of Education of five counties in Northcentral West Virginia.

The study was aimed at 9th grade students who were selected for two reasons. Work done by an epidemiologist from a local state Health Department showed that between the 7th and 9th grade there is a greater sexual awareness by both girls and boys (Nuzum, personal communication). Secondly, the 9th grade classes in most schools are smaller and therefore more suitable for presentations by groups from outside. However, because there were many requests for the programme and because of the need for such education, other groups of students were subsequently included.

The principal of each school in the five counties that had 9th grade students was sent a letter which informed him of the high incidence of venereal disease and sought permission to present the programme to his students. Parental approval was obtained by giving each student a permission slip which had to be returned to the principal only if the student was not to take part. 
Approximately 14 days before a presentation, students were asked 15 preliminary questions to test their general knowledge of venereal disease. On the day of the presentation they were first given a list of five 'values' (that is, 'a comfortable life,' 'having children, 'having a sound mind' etc.) each of which related to health. The students were then asked to rate these values in order of priority (1 being the most important, 5 being the least important). The students were asked if they could identify ways in which venereal diseases might affect any of these values.

The illustrated lecture dealt primarily with syphilis and gonorrhoea. The programme began by defining venereal disease and giving some general information. It then changed the emphasis to cover more specifically the incidence, causes, symptoms, and treatment. This first part of the programme lasted approximaely 30 minutes. Then the class was divided into smaller groups of 6-10 students, with a moderator from the Committee for Venereal Disease Education allocated to each group who would answer questions or talk individually to group members. He also conducted 'role playing' with the students by giving them hypothetical situations - such as pretending the students had just arrived at the clinic-to see how they would respond. He then provided a model for handling this situation. The moderator might also ask the students about various topics on venereal diseases.

After this 15-minute discussion, there was a formal summing up in which the entire class took part. This five-minute segment reviewed the cardinal signs and symptoms of syphilis and gonorrhoea and attempted to dispel myths about venereal disease. Finally, the programme gave the addresses of local facilities for diagnosing and treating venereal diseases and emphasised the confidential nature of such services. The importance of contact tracing was also explained. The class was then taken on a pictorial tour of a local clinic. Pamphlets summarising the programme and giving addresses of local treatment centres were then distributed. Two weeks after the presentation, a second test (identical with the preliminary one) was administered to the group by the class instructors; this was returned to the Committee for evaluation.

\section{Results}

During the last two years, 85 separate presentations have been given to 3210 students who ranged from 12 to 20 years of age ( 7 th to 12th grade). The students' knowledge of venereal disease was evaluated by using a selection of 15 multiple-choice questions for the preliminary and final tests. The

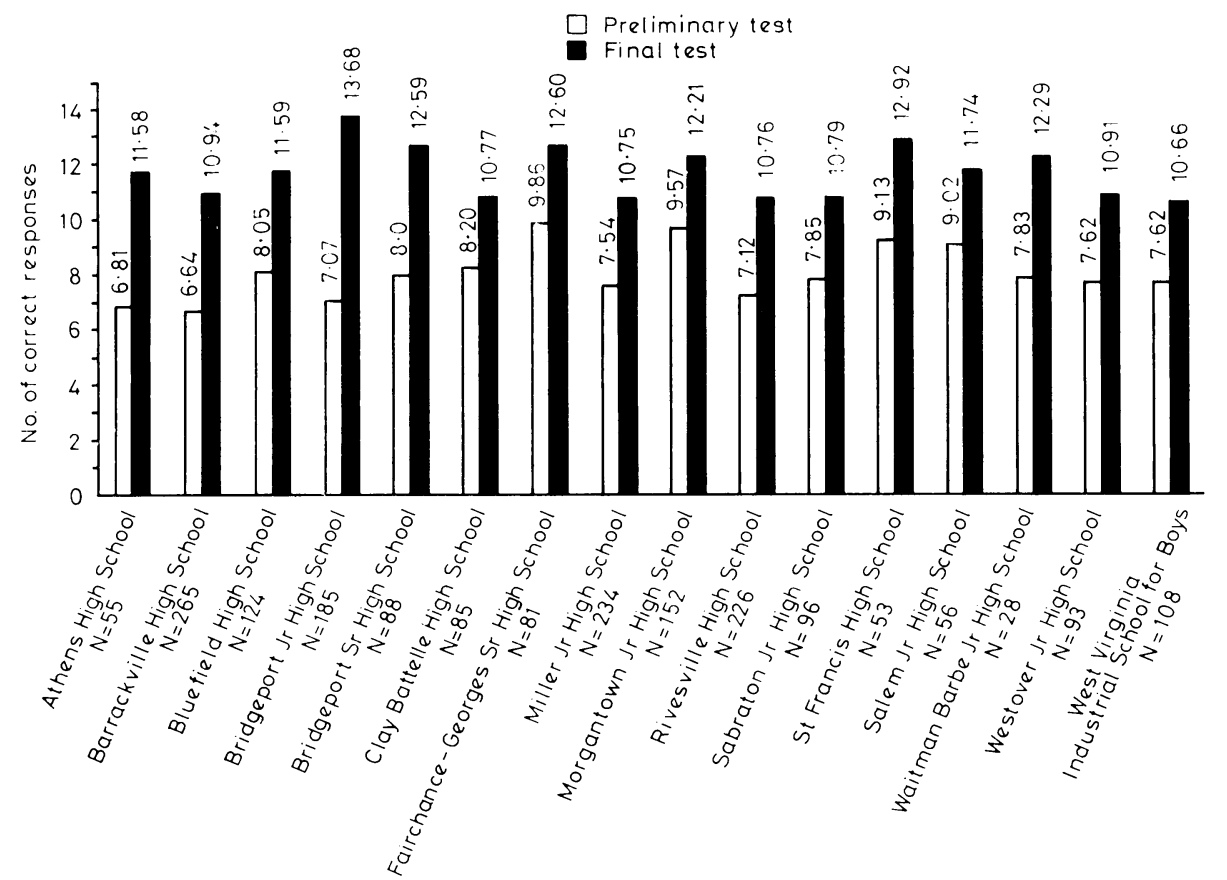

Fig. 1 Mean preliminary test and final test results. 
mean preliminary test score was $7.97\left(53^{\circ}{ }_{0}\right)$ correct answers out of 15 , and the mean final test score was $11.55\left(77_{0}^{\circ}\right)$ correct answers out of 15. Figure 1 shows some of the schools visited. The highest mean preliminary test score $(9 \cdot 86$ correct answers out of 15) was obtained by $10 \mathrm{th}, 11 \mathrm{th}$, and $12 \mathrm{th}$ graders at Fairchance-Georges Senior High School where the students had been given an introductory course earlier in the year. The highest mean final test score was obtained by 9 th graders at Bridgeport Junior High School where the instructor had included our programme as part of a teaching course on venereal disease. These rough scores suggest that all the students had better test scores after the presentations but they do not reflect what the students had learned.

To obtain a better evaluation of what the students had learned, the 15 questions in the preliminary and final tests were divided into four general categories and a question-by-question analysis was performed by comparing the percentage of students answering each question correctly in the preliminary test and the final test. The four categories consisted of:

1. Venereal disease in general

2. How venereal disease is contracted

3. Syphilis

4. Gonorrhoea.

There were three questions on venereal disease in general (Fig. 2). The most remarkable result was that to question number 14 which measured the student's knowledge of whether or not his parents had to be notified if he was treated for a venereal disease. In the preliminary test, only $47 \%$ of the students knew that by law no parent could be notified without their consent. After the presentation, $89 \%$ of the students knew this to be true.

Four questions dealt with the ways in which venereal disease is contracted (Fig. 3). These tested the students to see if they knew that: (1) it is transmitted by "skin to skin" contact; (2) it can be transmitted by either an infected man or woman; (3) syphilis and gonorrhoea can be present simul-

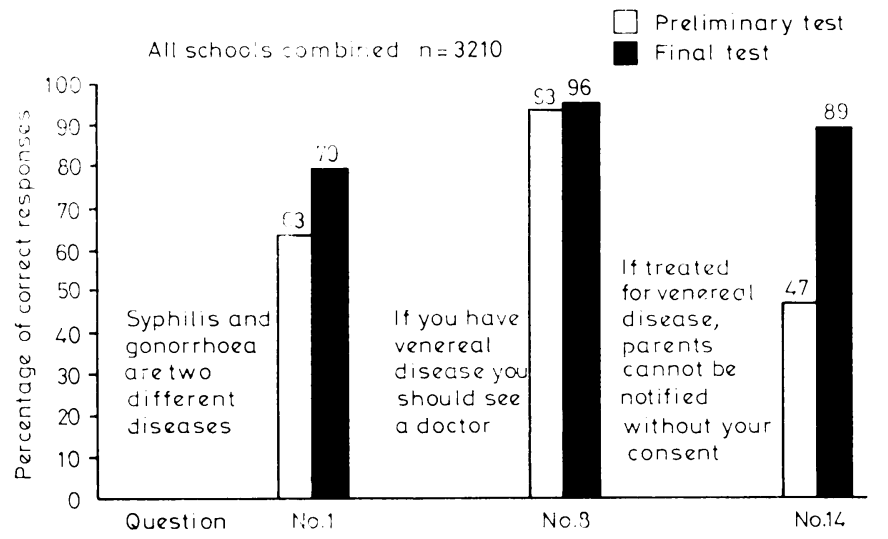

Fig. 2 Questions dealing with venereal disease in general.

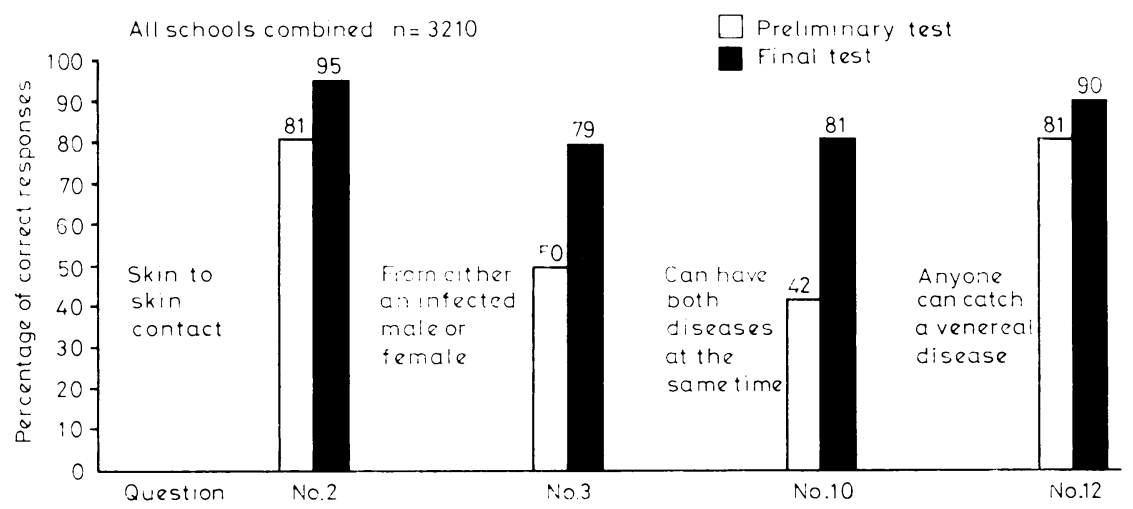

Fig. 3 Questions dealing with how venereal disease is contracted. 
taneously; (4) no one is immune to venereal disease. In the preliminary test, only $42 \%$ of the students knew that gonorrhoea and syphilis could occur simultaneously but by the final test $81 \%$ knew this was correct.

Originally five questions dealt with syphilis. However one of these was found to confuse the students and so it was not used in the results for 1975-76 (Fig. 4a). It dealt with the location of the first sign of syphilis. In 1976-77 the question was changed so the answers to question number 9 were from a smaller number of students (Fig. 4b). The other questions tested the students to see if they knew: (1) the first sign of primary syphilis; (2) that treatment is still required even though symptoms of syphilis have resolved; (3) that an unborn child can be affected by syphilis; and (4) untreated syphilis can lead to insanity. In the preliminary test, only $66 \%$ of the students knew that treatment for syphilis was required after the first stage had resolved; $90 \%$ of the students knew this after the presentation.

The last group of three questions dealt with gonorrhoea (Fig. 5). These tested to see if the students: (1) could identify the disease by its symptoms; (2) understood that untreated gonorrhoea could lead to sterility; or (3) knew that gonorrhoea was the most widespread communicable disease. The most striking result was the fact that in the preliminary test only $22 \%$ of the students knew gonorrhoea was the most widespread communicable disease. After the presentation, $66 \%$ of the students understood its severity.

To evaluate what knowledge had been retained, 53 students who had attended the programme as 9 th graders were tested again a year later without being told beforehand. Originally, their mean score in the preliminary test had been $9 \cdot 34(62 \%)$ correct answers out of 15 and their mean final test score $12.63(84 \%)$ correct out of 15 . One year later,

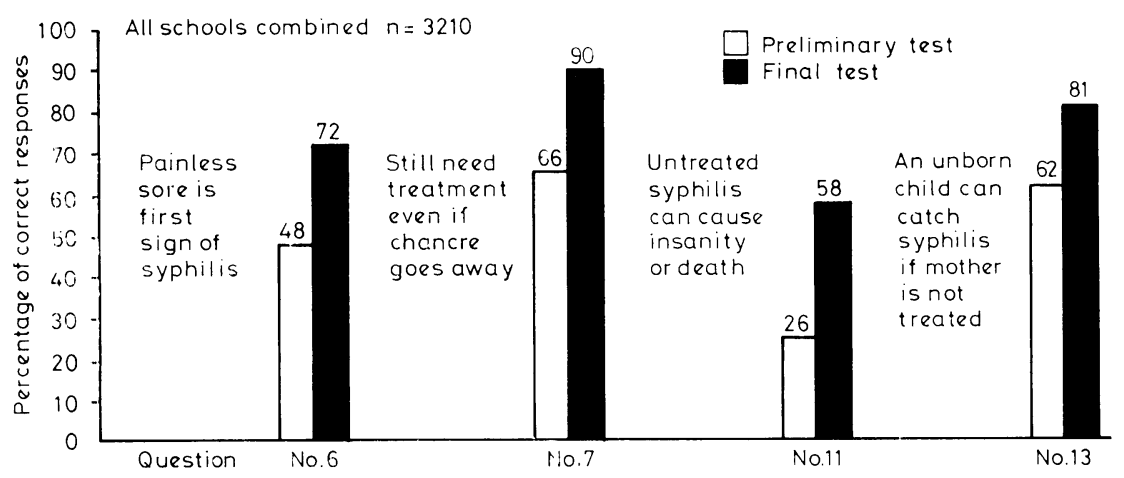

Fig. 4a Questions dealing with syphilis.

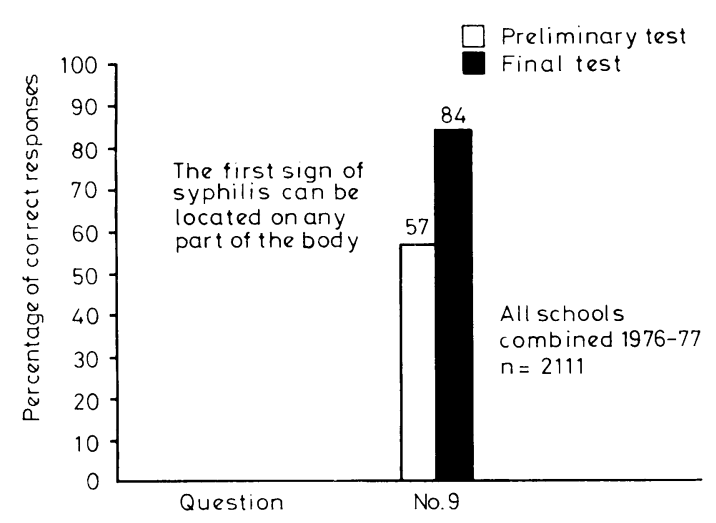

Fig. 4b Questions dealing with syphilis. the students' mean score in the final test was 11.41 $(76 \%)$ correct out of 15 (Fig. 6). Again a large percentage of the students answered the questions dealing with the signs and symptoms of syphilis and gonorrhoea correctly. The students found the questions about the results of untreated venereal disease difficult - a point that is often not stressed. Overall, $75 \%$ or more of the students answered 10 of the 15 questions correctly and 13 of the 15 questions were answered correctly by $61 \%$ or more of the students, one year after the programme.

\section{Discussion}

It is generally accepted that education influences disease prevalence to some extent (Simmons, 1971). It is also known that making students take part in 


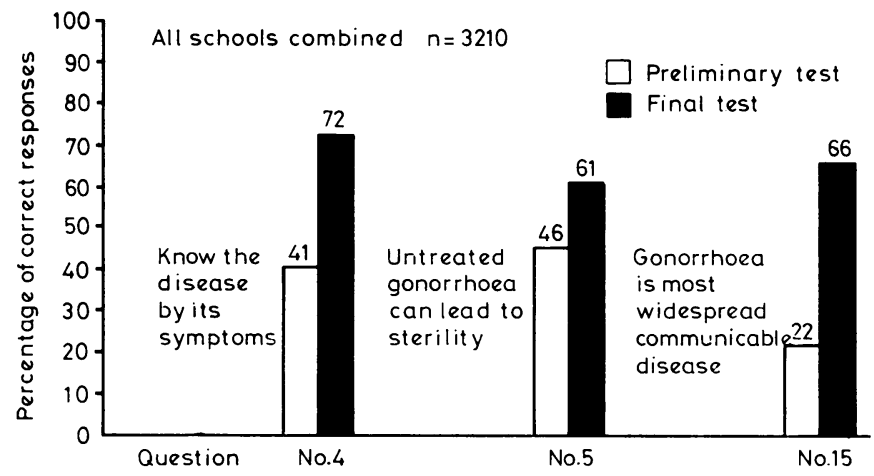

Fig. 5 Questions dealing with gonorrhoea.

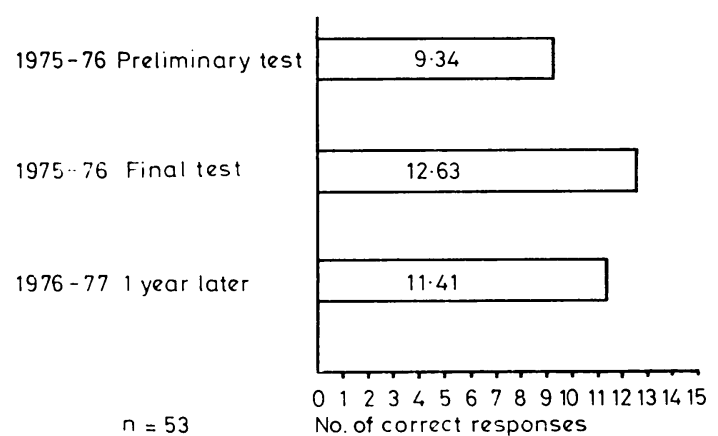

Fig. 6 Mean preliminary test and final test results compared with the results to the same tests one year later (at one school).

performance tests, discussions, and self improvement analysis is more effective than merely providing information in the form of pamphlets (Snegroff, 1975). In addition to providing the right kind of venereal disease education, a better understanding of the attitudes of young people towards sexual matters and a more open attitude towards the topic of venereal disease are needed.

The facts about syphilis and gonorrhoea, as well as other sexually transmitted diseases, are relatively straightforward and can easily be learned and retained, as shown by our study. Therefore, besides providing the facts, venereal disease education must give the following:

1. A feeling of trust when approaching a health professional for treatment

2. An understanding of the importance of contact tracing and how it works

3. An understanding of the function of a clinic

4. The knowledge that venereal diseases are ordinary conditions that doctors see and treat every day.
These extra necessities can be met by the use of small discussion groups as illustrated in this paper. It is often stated that if a teenager himself seeks treatment for a venereal disease, it will probably be the first time that he has sought medical help without his parents. The impression the teenager receives from the moderator from the Committee for Venereal Disease Education will often influence his opinion of health professionals and his trust in them. Small group sessions should be carried out only by mature and responsible individuals who understand the emotions and needs of the teenager. Until venereal disease can be accepted as just an illness and without the present stigma, we will continue to have a serious problem. Public awareness may prove to be a major factor contributing to the eventual decline in the prevalence of venereal disease.

We wish to acknowledge the assistance of members of the Committee for Venereal Disease Education of the West Virginia University Medical Center and to thank the West Virginia State Department of Health and State Department of Education for their assistance in the development and evaluation of our venereal disease education programme. We are grateful to the Bureau of Health Education of the Center for Disease Control for their financial support over the last two years and the assistance of the American Medical Student Association for administration of these funds.

\section{References}

Simmons, S. K. (1971). A viewpoint-Patient education-Vital, but more needed. Geriatrics, 26, 29-30.

Snegroff, S. (1975). Venereal disease education: Facts are not enough. Journal of School Health, 45, 37-39. 